\section{Kidney \\ Blood Pressure Research}

Kidney Blood Press Res 2014;39:630-635

DOI: $10.1159 / 000368475$

Published online: December 15, 2014

Accepted: November 28, 2014

\title{
Blood Pressure and Intracranial Aneurysms in Autosomal Dominant Polycystic Kidney Disease
}

\author{
Mariusz Niemczyk ${ }^{\mathrm{a}} \quad$ Tomasz Pilecki $^{\mathrm{a}} \quad$ Monika Gradzik ${ }^{\mathrm{b}} \quad$ Maciej Bujko ${ }^{c}$ \\ Stanisław Niemczyk ${ }^{d}$ Leszek Pączek ${ }^{a}$
}

aDepartment of Immunology, Transplant Medicine and Internal Diseases; 'bepartment of Radiology; Medical University of Warsaw; ' Department of Neurosurgery, The Medical Centre of Postgraduate Education; dDepartment of Internal Diseases, Nephrology and Dialysis; Military Institute of Medicine, Warsaw, Poland

\section{Key Words}

Ambulatory blood pressure monitoring - Arterial hypertension - Autosomal dominant polycystic kidney disease - Intracranial aneurysm - Magnetic resonance angiography of the brain

\begin{abstract}
Background/Aims: Autosomal dominant polycystic kidney disease (ADPKD) is correlated with an increased frequency of both intracranial aneurysms (ICANs), and arterial hypertension (AH). The aim of our study was to search for the association between blood pressure (BP) and ICANs in ADPKD patients. Methods: Sixty-eight adult, pre-dialysis phase ADPKD patients underwent both screening for ICANs with magnetic resonance angiography of the brain, and ambulatory blood pressure monitoring (ABPM). Results: ICANs were diagnosed in 10 patients (ICAN $(+)$ group), while in 58 were not (ICAN(-) group). The nighttime maximum diastolic blood pressure (DBP), maximum increase in DBP from measurement to measurement (positive delta of DBP) at night, and the standard deviation of the daytime mean arterial pressure were significantly higher in ICAN $(+)$ compared to ICAN(-) patients. Additionally, in a subgroup of patients after 45 years-of-age, ICAN $(+)$ patients had significantly higher maximum 24-hour and daytime systolic blood pressure, maximum 24-hour, daytime, nighttime DBP, maximum daytime and nighttime positive delta of DBP compared to ICAN(-) cases. Conclusions: Development of ICANs in hypertensive ADPKD patients is accompanied with higher values of some BP parameters measured by ABPM. Hypertensive ADPKD patients with substantial fluctuations in $B P$ assessed by $A B P M$, especially those after 45 years-of-age, should become candidates for screening for ICANs.
\end{abstract}




\section{Kidney \\ Blood Pressure Research}

\begin{tabular}{l}
\hline Kidney Blood Press Res 2014;39:630-635 \\
\hline \begin{tabular}{l|l} 
DOI: $10.1159 / 000368475$ & (c) 2014 S. Karger AG, Basel \\
www.karger.com/kbr
\end{tabular} \\
\hline Publisned online: December 15, 2014
\end{tabular}

Niemczyk et al.: BP and ICANs in ADPKD

\section{Introduction}

Autosomal dominant polycystic kidney disease (ADPKD) is the most common monogenic disease and affects 1 in 1000 individuals in the general population. ADPKD leads to end stage renal disease in a large proportion of patients, however it is not limited to the kidney. Extrarenal manifestations include, among others, cysts in other organs, for example liver and pancreas, intracranial aneurysms (ICANs), and arterial hypertension (AH). ADPKD is a consequence of a mutation in polycystin-1 or 2 gene [1]. Vascular manifestations of the disease are due to the fact that both polycystins are expressed within arterial smooth muscle cells [2-4], and a systemic vascular defect was observed already on oligosymptomatic stage of the disease [5, 6]. In effect, ADPKD patients are at risk for arterial complications [7].

The frequency of ICANs is increased in ADPKD compared to the general population [8] and is estimated to $4-22.5 \%[9,10]$. The subarchnoid hemorrhage (SAH) due to the rupture of ICAN in ADPKD occurs more often and at younger age compared to the general population $[11,12]$, and is connected to high risk of death or serious complications $[13,14]$. The overall prevalence of AH in ADPKD may exceed 80\% [15]. AH is a well-known risk factor for both the progression of chronic kidney disease (CKD) [16], and cardiovascular complications [17, 18], which are the main cause of death in ADPKD population in the dialysis era [19].

Although $\mathrm{AH}$ is a risk factor for SAH in the general population [20], it is not considered as a risk factor for ICANs formation in ADPKD $[11,21]$. We attempted to verify that thesis in a group of ADPKD patients in which both screening for ICANs with magnetic resonance (MR) angiography of the brain, and assessment of blood pressure (BP) with ambulatory blood pressure monitoring (ABPM) were carried out.

\section{Materials and Methods}

In 68 patients, $25(36.8 \%)$ male and 43 (63.2\%) female, with ADPKD diagnosed according to the unified ultrasonographic criteria [22] both MR angiography of the brain, and ABPM have been performed between June 2009 and October 2012. The design and results of the MR study have already been reported [23]. ABPM examinations were carried out at the Medical University of Warsaw's Department of Immunology, Transplant Medicine and Internal Diseases using Space Labs devices, models 90207, or 90217; and analyzed with ABP Report Management System (Space Labs Medical, Inc.), version 1.03.16, software. Data on minimal, mean, and maximal diastolic blood pressure (DBPmin, DBPmean, and DBPmax, respectively), minimal, mean, and maximal systolic blood pressure (SBPmin, SBPmean, and SBPmax, respectively), minimal, mean, and maximal mean arterial pressure (MAPmin, MAPmean, and MAPmax, respectively), minimal, mean, and maximal heart rate (HRmin, HRmean, and HRmax, respectively), were recorded for each case. Additionally, standard deviations (SD) for DPB ( $\left.\mathrm{DBP}_{\mathrm{SD}}\right), \mathrm{SBP}\left(\mathrm{SBP}_{\mathrm{SD}}\right)$, MAP $\left(\mathrm{MAP}_{\mathrm{SD}}\right)$, and $\mathrm{HR}\left(\mathrm{HR}_{\mathrm{SD}}\right)$ in the 24 hours, during the daytime, and during the nighttime were analysed. We also calculated 24-hour pulse pressure (24hPP), and maximum daytime and nighttime increases in SBP and DBP from measurement to measurement (positive deltas of SBP and DBP).

All included patients were Caucasians and all were in pre-dialysis period of the disease. The mean age was 45.01 \pm 14.70 years (range 19-75 years). Mean glomerular filtration rate (GFR), calculated according to the Chronic Kidney Disease Epidemiology Collaboration (CKD-EPI) formula, was $67.68 \pm 33.54 \mathrm{ml} / \mathrm{min}$ (range 15.7-139.8 ml/min), with 19 (27.9\%), 19 (27.9\%), 20 (29.4\%), 10 (14.7\%), and 0 (0\%) patients in the $1^{\text {st }}, 2^{\text {nd }}, 3^{\text {rd }}, 4^{\text {th }}$, and $5^{\text {th }}$ stage of CKD, respectively. Fourty-six $(67.6 \%)$ patients were previously diagnosed with AH and treated with antihypertensive agents, while $22(32.4 \%)$ patients were regarded as normotensives. Patients with SAH in their medical history were not included into the analysis.

\section{Ethical Statement}

The study was conducted in accordance to the principles of Declaration of Helsinki, and its protocol was approved by the Ethics Committee of the Medical University of Warsaw. All patients gave written informed consent for the inclusion to the study. 


\section{Kidney Blood Pressure Research}

Table 1. Characteristics of groups

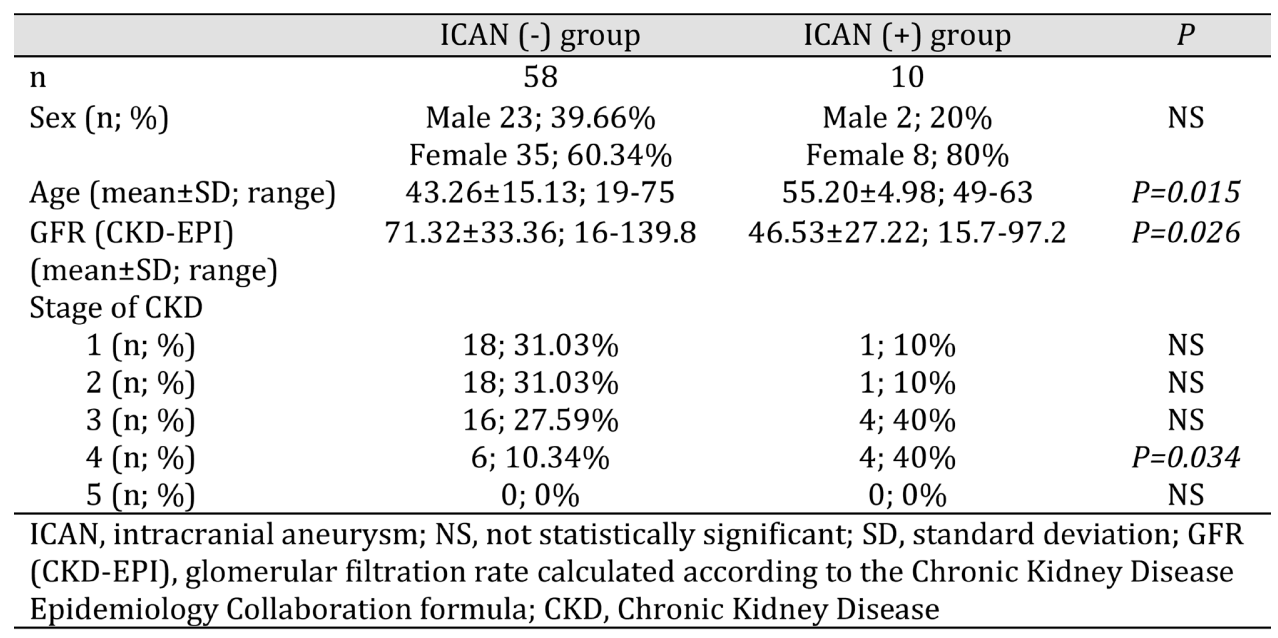

\section{Statistical analysis}

Statistical analysis was performed using Statistica, ver. 10, software. The Mann-Whitney U and Fisher's exact tests were used when appropriate. $P<0.05$ was considered statistically significant. Results were presented as mean \pm standard deviation (SD), unless otherwise stated.

\section{Results}

Ten patients were diagnosed with ICANs (ICAN (+) group), while in 58 were not (ICAN (-) group). The comparison of these both groups is shown on Tab.1. When comparing ABPM parameters, significant differences were found in nighttime DBPmax $(91.90 \pm 11.38$ in ICAN $(+)$ vs $84.48 \pm 11.44 \mathrm{mmHg}$ in ICAN $(-) ; P=0.045)$, max $\triangle$ DBPnight $(19.10 \pm 6.98$ in ICAN $(+)$ vs $15.09 \pm 6.75 \mathrm{mmHg}$ in ICAN $(-) ; P=0.027)$, and daytime $\mathrm{MAP}_{\mathrm{SD}}(11.15 \pm 3.78$ in ICAN $(+)$ vs $8.67 \pm 2.18 \mathrm{mmHg}$ in ICAN $(-) ; P=0.030)$. However, these groups were not fully comparable; in the ICAN $(+)$ group, the mean age was significantly higher, and the kidney function assessed by GFR significantly worse compared to the ICAN (-) group (Tab. 1). While ICANs were detected only in patients above 45 years-of-age, we decided to perform further analysis in subgroups of patients older than 45 years (ICAN (+) group; and ICAN (-) 45+ subgroup), in which the demographic and renal function parameters were comparable, as shown on Tab. 2. During ABPM, the ICAN (+) patients had significantly higher 24-hour SBPmax (172.70 \pm 29.54 vs $150.50 \pm 11.29 \mathrm{mmHg} ; P=0.011)$, DBPmax $(111.20 \pm 20.59$ vs $97.54 \pm 8.76$ mmHg; $P=0.047), D_{\mathrm{SD}}(11.49 \pm 2.68$ vs $9.34 \pm 1.75 \mathrm{mmHg} ; P=0.021)$, MAPmax (132.00 \pm 21.04 vs $115.86 \pm 8.28 \mathrm{mmHg} P=0.008)$, and $\mathrm{MAP}_{\mathrm{SD}}(12.24 \pm 3.06$ vs $10.05 \pm 2.02 \mathrm{mmHg} ; P=0.035)$ compared to ICAN (-) 45+ subgroup. At the nighttime, the ICAN(+) group had significantly higher DBPmax (91.90 \pm 11.38 vs $81.04 \pm 10.21 \mathrm{mmHg} ; P=0.013)$, $\max \Delta \mathrm{DBP}(19.10 \pm 6.98$ vs $13.32 \pm 3.81 \mathrm{mmHg} ; P=0.013)$ and MAPmax $(108.50 \pm 15.74$ vs $97.14 \pm 11.37 \mathrm{mmHg} ; P=0.027)$ compared to ICAN (-) 45+ subgroup. Similarly, during the daytime, SBPmax $(172.70 \pm 29.55$ vs $150.50 \pm 11.29 \mathrm{mmHg} ; P=0.011)$, DBPmax $(111.20 \pm 20.59$ vs $97.54 \pm 8.76 \mathrm{mmHg} ; P=0.047)$, DBP $_{\text {SD }}(10.15 \pm 3.06$ vs $7.71 \pm 1.99 \mathrm{mmHg} ; P=0.023)$, $\max \Delta \mathrm{DBP}(25.00 \pm 8.94$ vs $18.64 \pm 5.88$ mmHg; $P=0.035)$, MAPmax (132.00 \pm 21.04 vs $115.71 \pm 8.16 \mathrm{mmHg} ; P=0.007)$, and $\mathrm{MAP}_{\mathrm{SD}}$ $(11.15 \pm 3.78$ vs $8.48 \pm 2.49 \mathrm{mmHg} ; P=0.033)$ were significantly higher in ICAN $(+)$ patients then in patients older than 45 years-of-age without an ICAN. No statistically significant difference between groups was noted for HR, 24-hPP and max $\triangle \mathrm{SBP}$. 


\section{Kidney Blood Pressure Research}

Table 2. Characteristics of subgroups above 45 years-of-age

\begin{tabular}{|c|c|c|c|}
\hline & ICAN (-) 45+ group & ICAN (+) group & $P$ \\
\hline $\mathrm{n}$ & 28 & 10 & \\
\hline $\operatorname{Sex}(n ; \%)$ & $\begin{array}{c}\text { Male } 10 ; 35.71 \% \\
\text { Female } 18 \cdot 64.29 \%\end{array}$ & $\begin{array}{c}\text { Male } 2 ; 20 \% \\
\text { Female } 8: 80 \%\end{array}$ & NS \\
\hline Age (mean $\pm S D$; range) & $56.89 \pm 7.44 ; 47-75$ & $55.20 \pm 4.98 ; 49-63$ & NS \\
\hline $\begin{array}{l}\text { GFR (CKD-EPI) } \\
\text { (mean } \pm S D ; \text { range) }\end{array}$ & $55.35 \pm 24.80 ; 16-104.2$ & $46.53 \pm 27.22 ; 15.7-97.2$ & NS \\
\hline Stage of CKD & & & \\
\hline $1(n ; \%)$ & $3 ; 10.71 \%$ & $1 ; 10 \%$ & NS \\
\hline $2(\mathrm{n} ; \%)$ & $10 ; 35.71 \%$ & $1 ; 10 \%$ & NS \\
\hline $3(n ; \%)$ & $11 ; 39.29 \%$ & $4 ; 40 \%$ & NS \\
\hline $4(n ; \%)$ & $4 ; 14.29 \%$ & $4 ; 40 \%$ & NS \\
\hline $5(n ; \%)$ & $0 ; 0 \%$ & $0 ; 0 \%$ & NS \\
\hline
\end{tabular}

ICAN, intracranial aneurysm; NS, not statistically significant; SD, standard deviation; GFR (CKD-EPI), glomerular filtration rate calculated according to the Chronic Kidney Disease Epidemiology Collaboration formula; CKD, Chronic Kidney Disease

\section{Discussion}

In the previous paper [23], we attempted to search for risk factors for ICANs in ADPKD population. However, we failed to define the risk factors for ICANs except for age above 45 years. Arterial hypertension $(\mathrm{AH})$ also was not found a risk factor for ICANs, however only qualitative data on $\mathrm{AH}$ were taken into consideration, with patients divided into 3 subgroups: "no AH," "well-controlled AH," and "insufficiently controlled AH" [23]. In this study we used quantitative data on blood pressure parameters obtained by ABPM and noticed that ADPKD patients with ICANs have higher nighttime maximum DBP, higher maximum increases in nighttime DBP from measurement to measurement, and higher SD of the daytime MAP compared to those without ICANs. Additionally, in a subgroup of ADPKD patients above 45 years-of-age, those with ICANs have higher 24-hour SBPmax, DBPmax, DBP ${ }_{S D}, M_{A P m a x}$ and $\mathrm{MAP}_{\mathrm{SD}}$, higher nighttime DBPmax, max $\triangle \mathrm{DPB}$, and MAPmax, and higher daytime SBPmax, DBPmax, $\mathrm{DBP}_{\mathrm{SD}}$, max $\triangle \mathrm{DBP}, \mathrm{MAPmax}$ and $\mathrm{MAP}_{\mathrm{SD}}$ compared to those without. No significant difference between ICAN (+) and ICAN (-) patients were observed in HR, 24-hPP, maximal increases in SBP from measurement to measurement. Of note, while the differences between ICAN $(+)$ and ICAN $(-)$ patients were observed in maximum, but not mean, values of DBP and $\mathrm{SBP}$, they are rather episodic peaks in BP (maximum SBP/DBP or maximum increases in DBP from measurement to measurement this means in 20 minutes in the daytime and 45 minutes at night) than average SBP/DBP what accompany development of ICANs in ADPKD.

However, it should not be concluded that it is hypertension, of fluctuations of $\mathrm{BP}$, what causes the development of an ICAN in ADPKD. AH is not a necessary factor for the development of ICANs both in animal model of polycystic kidney disease [24], and in ADPKD patients [25]. Rather, development of ICANs and higher values of BP both reflects the severity of systemic cardiovascular dysfunction related to ciliopathy. AH in ADPKD has complex pathogenesis, with 3 main pathomechanisms: (1) activation of the renin-angiotensin-aldosterone system secondary to intrarenal ischemia caused by growing cysts, (2) activation of the sympathetic nervous system, and (3) ciliopathy-related endothelial dysfunction. Ciliopathy leads to endothelial dysfunction with impaired vascular relaxation [26], what may yield in elevated BP. Similarly, aneurysm formation is due to the primary cilia dysfunction in a mechanism dependent on downregulation of survivin expression [24].

Nevertheless, the clinical conclusion from our results is that hypertensive ADPKD patients with substantial fluctuations in BP measurements, especially made with ABPM, should become candidates for screening for ICANs. A detailed analysis of ABPM measurements 


\section{Kidney \\ Blood Pressure Research}

including maximum SBP/DBP values shown automatically by software and increases in DBP from measurement to measurement calculated manually may be helpful in selection of ADPKD patients who should undergo screening for ICANs. However, it should be emphasized that normotensive patients with ADPKD are also at risk for ICAN development [25].

In summary, we feel that hypertensive ADPKD patients with substantial fluctuations in BP assessed by ABPM as high maximum SBP/DBP values and/or high increases in DBP from measurement to measurement, especially those after 45 years-of-age, should become candidates for screening for ICANs. On the other hand, we identified only one of possible risk factors for ICANs, because, as reported previously, increased BP is not a necessary factor for the development of ICAN and its rupture $[13,25]$. A prospective study including larger number of cases is needed to confirm our findings and establish threshold values of BP suggesting high risk of development of an ICAN.

\section{Conclusions}

Due to the common, ciliopathy-related pathomechanism, development of ICANs in hypertensive ADPKD patients is accompanied with the higher values of some blood pressure parameters measured by ABPM. Hypertensive ADPKD patients with substantial fluctuations in $\mathrm{BP}$ assessed by ABPM as high maximum SBP/DBP values and/or high increases in DBP from measurement to measurement, especially those after 45 years-of-age, should become candidates for screening for ICANs.

\section{Disclosure Statement}

The authors declare that they have no conflict of interest.

\section{References}

$\checkmark 1$ Chang MY, Ong ACM: Autosomal dominant polycystic kidney disease: recent advances in pathogenesis and treatment. Nephron Physiol 2008;108:1-7.

2 Griffin MD, Torres VE, Grande JP, Kumar R: Vascular expression of polycystin. J Am Soc Nephrol 1997;8:616624.

- 3 Kim K, Drummond I, Ibraqhimov-Beskrovnaya 0, Klinger K, Arnaout MA: Polycystin 1 is required for the structural integrity of blood vessels. Proc Natl Acad Sci USA 2000;97:1731-7136.

4 Torres VE, Cai Y, Chen X, Wu GQ, Geng L, Cleghorn KA, Johnson CM, Somlo S: Vascular expression of polycystin-2. J Am Soc Nephrol 2001;12:1-9.

5 Ramunni A, Brescia P, Quaranta D, Bianco MS, Ranieri P, Dolce E, Coratelli P: Cutaneous microcirculation is impaired in early autosomal dominant polycystic kidney disease. Nephron Clin Pract 2009;113:c71-75.

6 Heffernan KS, Kuvin JT, Sarnak MJ, Perrone RD, Miskulin DC, Rudym D, Chandra P, Karas RH, Menon V: Peripheral augmentation index and vascular inflammation in autosomal dominant polycystic kidney disease. Nephrol Dial Transplant 2011;26:2515-2521.

-7 Roth C, Kleffmann J, Bergmann C, Deinsberger W, Ferbert A: Ruptured cerebral aneurysm and acute bilateral carotid artery dissection in a patient with polycystic kidney disease and polycystic liver disease. Cerebrovasc Dis 2013;35:590-591.

-8 Vlak MHM, Algra A, Brandenburg R, Rinkel GJE: Prevalence of unruptured intracranial aneurysms, with emphasis on sex, age, comorbidity, country, and the time period: a systematic review and mets-analysis. Lancet Neurol 2011;10:626-636.

-9 Chapman AB, Rubinstein D, Hughes R, Stears JC, Earnest MP, Johnson AM, Gabow PA, Kaehny WD: Intracranial aneurysms in autosomal dominant polycystic kidney disease. N Engl J Med 1992;327:916-920. 


\section{Kidney \\ Blood Pressure Research}

10 Belz MM, Fick-Brosnahan GM, Hughes RL, Rubinstein D, Chapman AB, Johnson AM, McFann KK, Kaehny WD, Gabow PA: Recurrence of intracranial aneurysms in autosomal-dominant polycystic kidney disease. Kidney Int 2003;63:1824-1830.

11 Rinkel GJE: Intracranial aneurysm screening: indications and advice for practice. Lancet Neurol 2005;4:122-28.

-12 Schievink WI, Torres VE, Piepgras DG, Wiebers DO: Saccular intracranial aneurysms in autosomal dominant polycystic kidney disease. J Am Soc Nephrol 1992;3:88-95.

-13 Gieteling EW, Rinkel GJE: Characteristics of intracranial aneurysms and subarachnoid heamorrhage in patients with polycystic kidney disease. J Neurol 2003;250:418-423.

14 Zuka M, Onoe T, Kawano M, Yamagishi M, Ohshima T: Sudden death of a young male with previously undiagnosed autosomal dominant polycystic kidney disease (ADPKD). Leg Med (Tokyo) 2011;13:35-38.

-15 Ecder T, Schrier RW: Hypertension in autosomal-dominant polycystic kidney disease: Early occurence and unique aspects. J Am Soc Nephrol 2001;12:194-200.

16 Helal I, Reed B, Schrier RW: Emergent early markers of renal progression in autosomal-dominant polycystic kidney disease patients: Implications for prevention and treatment. Am J Nephrol 2012;36:162167.

17 MacMahon S, Peto R, Cutler J, Collins R, Sorlie P, Neaton J, Abbott R, Godwin J, Dyer A, Stamler J: Blood pressure, stroke, and coronary heart disease. Part 1, Prolonged differences in blood pressure: prospective observational studies corrected for the regression dilution bias. Lancet 1990;335:765-774.

18 Lewington S, Clarke R, Qizilbash N, Peto R, Collins R; Prospective Studies Collaboration: Age-specific relevance of usual blood pressure to vascular mortality: a meta-analysis of individual data for one million adults in 61 prospective studies. Lancet 2002;360:1903-1913.

19 Fick GM, Johnson AM, Hammond WS, Gabow PA: Causes of death in autosomal dominant polycystic kidney disease. J Am Soc Nephrol 1995;5:2048-2056.

-20 Steiner T, Juvela S, Unterberg A, Jung C, Forsting M, Rinkel G: European Stroke Organization guidelines for the management of intracranial aneurysms and subarachnoid haemorrhage. Cerebrovasc Dis 2013;35:93112.

-21 Xu HW, Yu SQ, Mei CL, Li MH: Screening for intracranial aneurysm in 355 patients with autosomaldominant polycystic kidney disease. Stroke 2011;42:204-206.

22 Pei Y, Obaji J, Dupuis A, Paterson AD, Magistroni R, Dicks E, Parfrey P, Cramer B, Coto E, Torra R, San Millan JL, Gibson R, Breuning M, Peters D, Ravine D: Unified criteria for ultrasonographic diagnosis of ADPKD. J Am Soc Nephrol 2009;20:205-212.

23 Niemczyk M, Gradzik M, Niemczyk S, Bujko M, Gołębiowski M, Pączek L: Intracranial aneurysms in autosomal dominant polycystic kidney disease. AJNR Am J Neuroradiol 2013;34:1556-1559.

24 Aboualaiwi WA, Muntean BS, Ratnam S, Joe B, Liu L, Booth RL, Rodriguez I, Herbert BS, Bacallao RL, Fruttiger M, Mak TW, Zhou J, Nauli SM: Survivin-induced abnormal ploidy contributes to cystic kidney and aneurysm formation. Circulation 2014;129:660-672.

25 Chauveau D, Pirson Y, Verellen-Dumoulin C, Macnicol A, Gonzalo A, Grunfeld JP: Intracranial aneurysms in autosomal dominant polycystic kidney disease. Kidney Int 1994;45:1140-1146.

-26 Rahbari-Oskoui F, Williams 0, Chapman A: Mechanisms and management of hypertension in autosomal dominant polycystic kidney disease. Nephrol Dial Transplant 2014;29:2194-2201. 